\title{
A pearly papule with telangiectasia
}

Alvin Lim, James Muir

\section{CASE}

A man aged 52 years with a history of non-melanoma skin cancer presented for a skin examination. He had a history of chronic sun exposure since childhood. He had no history of melanoma. He had no other comorbidities and did not take any regular medications. On examination, he had extensive sun-damaged skin on his face. On the left lateral aspect of the chin there was a firm, non-tender, skin-coloured papule (Figure 1). He was unaware of this lesion.

\section{QUESTION 1}

What is the differential diagnosis for a skin-coloured facial papule?

\section{QUESTION 2}

What features would you look for on dermoscopy to differentiate between causes of skin-coloured facial papules?

\section{ANSWER 1}

The clinical differential diagnosis for this lesion includes:

- basal cell carcinoma (BCC)

- amelanotic melanoma

- intradermal naevus

- angiofibroma (fibrous papule of the face)

- adnexal tumours

- sebaceous hyperplasia.

\section{ANSWER 2}

Dermoscopy reveals diagnostic features invisible to the naked eye or loupe magnification. BCC, intradermal naevi, sebaceous hyperplasia and amelanotic malignant melanoma typically show distinctive dermoscopic features that allow differentiation. Table 1 outlines the distinguishing features for the differential diagnosis for a non-pigmented facial papule.

\section{CASE CONTINUED}

The lesion was examined with non-polarised contact dermoscopy (Figure 2). On dermoscopy, there was a pearly papule measuring $2 \mathrm{~mm}$ with branching blood vessels (arborising telangiectasia). The papule was abutting a hair follicle. Of note, there was background sun-damaged skin characterised by erythema, pink-red pseudonetwork (annular pigmentation that resembles a network, surrounding white areas corresponding to follicular openings), unfocused blood vessels and
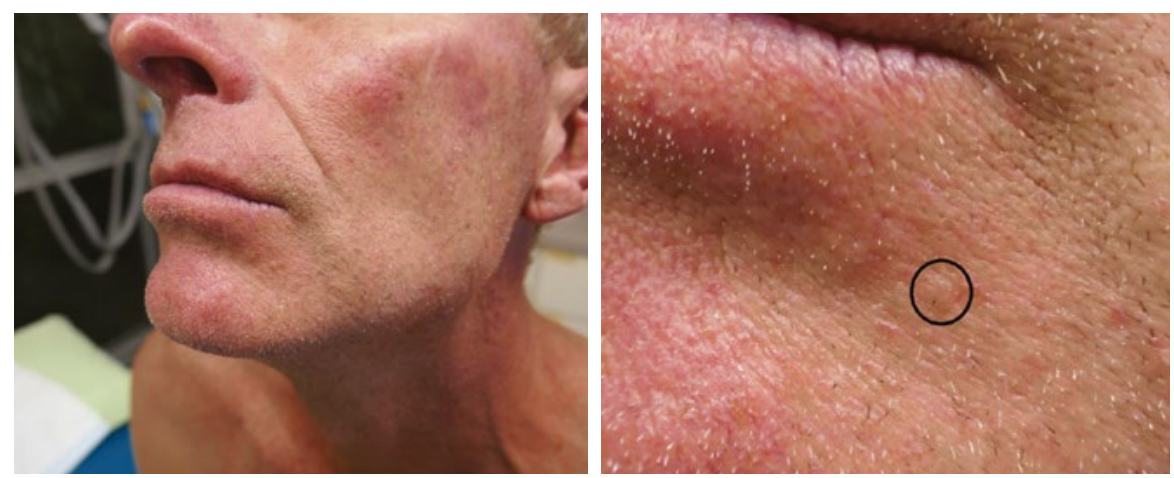

Figure 1. A pearly papule white halo structures around yellow (keratin-filled) follicular openings. ${ }^{1}$

\section{QUESTION 3}

What is the presumptive diagnosis at this stage?

\section{QUESTION 4}

What is the next step in management?

\section{ANSWER 3}

$\mathrm{BCC}$ is the presumptive diagnosis in a high-risk patient with multiple non-melanoma skin cancers and chronic sun exposure. It is commonly diagnosed by clinical and dermoscopic examination.

Clinically, BCC appears shiny and pearly (translucent), which can be made more obvious by stretching the surrounding skin.

On dermoscopy, a pinkish hue and arborising telangiectasia are common 


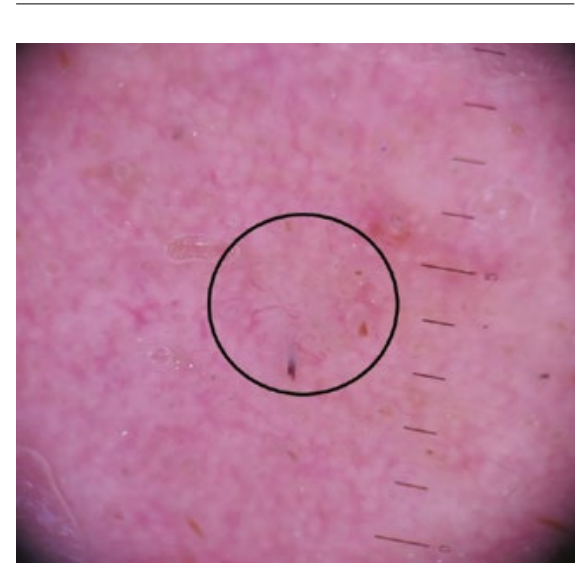

Figure 2. Dermoscopic view of the papule features, as seen in this case. In addition, non-pigmented BCC may display focal ulceration, white shiny perpendicular lines (seen with polarised dermoscopy) and structureless white areas. ${ }^{2}$

Therefore, the patient in this case had a small $(2 \mathrm{~mm})$ facial lesion that is clinically and dermoscopically suspicious for BCC.

\section{ANSWER 4}

The diagnosis of BCC should be confirmed histologically.

Consideration should be given to the size, shape and site of the lesion when deciding on biopsy technique. ${ }^{3}$ Where possible, for clinically suspected

\section{Table 1. Differential diagnoses for a non-pigmented facial papule}

Basal cell $\quad$ BCC is the most common skin malignancy. It is associated with chronic carcinoma (BCC) sun exposure and most commonly occurs on the head and neck. Predisposing factors include fair skin, male sex, age $>50$ years, prior history of skin cancer, exposure to ionising radiation or arsenic, scars and immunosuppression. ${ }^{4}$

Dermoscopic features include arborising telangiectasia, focal ulceration, white structureless areas and white perpendicular lines. ${ }^{2}$

\section{Amelanotic $\quad$ AM may mimic BCC clinically. Lacking pigment, AM may appear as a melanoma (AM) nodule that is skin-coloured, pink, or red. Dermoscopically, the vascular pattern may help distinguish AM from benign, nonpigmented lesions, particularly the presence of linear irregular vessels and milky red globules.10,11}

Intradermal Intradermal naevus is a benign melanocytic proliferation that appears as naevus a nodule that is skin-coloured, pink or light brown. Dermoscopically, it may have cobblestone, globular or structureless pigmentation. Comma vessels or arborising vessels may be observed, but they lack other BCCspecific features. ${ }^{12}$ It is usually present from adolescence without history of change.

Angiofibroma Angiofibroma, also called fibrous papule, is a benign tumour caused by proliferation of fibroblasts, collagen and dilated blood vessels in the dermis. ${ }^{13}$ Usually $<5 \mathrm{~mm}$ in size, it appears commonly on the face as a shiny, smooth skin-coloured or pink papule. Dermoscopy may show a milky-white or pink background with telangiectasia. ${ }^{13}$

Adnexal tumour Adnexal tumours are rare tumours affecting the hair follicles, sebaceous glands and sweat glands. Microcystic adnexal carcinoma (MAC) is a malignant tumour that typically occurs on the central part of the face in people who have had chronic ultraviolet light exposure. It may present as a slowly growing, pearly nodule on the head and neck. Benign tumours include spiroadenoma, trichoepithelioma and trichodiscoma. Dermoscopic features of these tumours overlap with BCC, including white structures, blue-grey dots or globules, linear or branching vessels. ${ }^{14}$

Sebaceous Sebaceous hyperplasia appears clinically as a pearly papule on hyperplasia the forehead and cheeks of elderly individuals. Dermoscopically, it is distinguished from BCC by multiple white-yellow globules and branching vessels that do not cross the centre (a follicular opening). ${ }^{15}$ non-melanoma skin cancer, complete excision of the lesion is recommended as per the Australian Cancer Council Guidelines in order to facilitate assessment of its nature and extent. ${ }^{4}$ For small lesions, an excisional biopsy with an appropriate margin serves as both a diagnostic test and definitive treatment. If this is not possible, a partial biopsy from the centre of the lesion is preferred, with a view to definitive management following histological examination. $^{5}$

\section{CASE CONTINUED}

The lesion was excised with an ellipse with $2 \mathrm{~mm}$ margins with the intent of achieving definitive treatment. The specimen was sent for histology.

On histopathology, no malignancy was found on initial examination. Further examination of multiple superficial and deep sections did not reveal evidence of malignancy. The lesion was diagnosed as a benign fibrous papule with surrounding solar elastosis and telangiectasia.

\section{QUESTION 5}

What are the consequences of an incorrect diagnosis? What are the risks for excisional biopsy as a diagnostic and treatment modality?

\section{QUESTION 6}

How accurate is clinical and dermoscopic detection of skin cancer?

\section{ANSWER 5}

An incorrect diagnosis of skin cancer using visual inspection and dermoscopy may lead to unnecessary excision, inappropriate treatment (eg non-surgical treatments) and patient anxiety. ${ }^{6}$ The risk of excisional biopsy includes subjecting the patient to an invasive procedure and its associated consequences - scar and wound management, risk of infection, cosmetic disfigurement, functional impairment and expense. The size of the resulting skin defect should be considered when deciding whether this method is appropriate. If surgery will produce a significant scar, then consideration should be given to an initial biopsy. 


\section{ANSWER 6}

Dermoscopy increases the accuracy of skin cancer detection when added to visual inspection. ${ }^{6}$ A meta-analysis reported the sensitivity and specificity of dermoscopy for detecting BCC to be $91.2 \%$ and $95 \%$, respectively. ${ }^{7}$ Adding dermoscopy to visual inspection with the naked eye increased both sensitivity (from $66.9 \%$ to $85 \%$ ) and specificity (from $97.2 \%$ to $98.2 \%$ ). ${ }^{7}$

Although various dermoscopic algorithms have been published to aid melanoma diagnosis, there is no clear evidence that one is superior. A 2016 Cochrane review indicated no improvement in using a dermoscopic checklist for melanoma diagnosis versus clinician experience. ${ }^{8}$ A comparative study reports modest accuracy for six common algorithms for detecting melanoma (ABCD [asymmetry, border, colour, diameter], Menzies, 7-point checklist, 3-point checklist, Chaos and Clues, CASH [colour, architecture, symmetry, homogeneity]). ${ }^{9}$ Although dermoscopy may improve clinical diagnostic accuracy, interpretation of visual and dermoscopic features remains subjective, with poor interobserver agreement.

\section{Key points}

- Facial papules have a broad range of potential benign and malignant diagnoses.

- A pearly papule with telangiectasia on the face of a patient with risk factors for skin cancer should raise suspicion for malignancy.

- Clinical diagnosis of skin cancer has limitations, and it is important for clinicians to be aware of the possibility of diagnostic error in order to consider the most appropriate management.

\section{Authors}

Alvin Lim MD, FRACGP, General Practitioner, Qld. alvinlimdr@gmail.com

James Muir MBBS, FACD, FACRRM (Hon), Director, Department of Dermatology, Mater Hospital, Qld; Dermatologist, Tele-derm National online; Senior Lecturer, University of Queensland, QId

Competing interests: None.

Funding: None.

Provenance and peer review: Not commissioned externally peer reviewed.

\section{Acknowledgements}

The authors would like to thank Dr Louis Pool from Sullivan Nicolaides pathology for providing the histopathology report.

\section{References}

1. Dimitriou F, Deinlein T, Zalaudek I. Actinic keratosis. Auenbruggerpl, Graz: Dermoscopedia, 2019. Available at https://dermoscopedia.org/w/ index.php?title=Actinic_keratosis\&oldid=16421 [Accessed 14 February 2020].

2. DermNet NZ. Dermoscopy of basal cell carcinoma. Hamilton, NZ: DermNet NZ, 2008. Available at www.dermnetnz.org/cme/dermoscopy-course/ dermoscopy-of-basal-cell-carcinoma [Accessed 14 February 2020].

3. Clarke P. Nonmelanoma skin cancers - Treatment options. Aust Fam Physician 2012;41(7):476-80.

4. Cancer Council Australia and Australian Cancer Network. Basal cell carcinoma, squamous cell carcinoma (and related lesions) - A guide to clinical management in Australia. Sydney: Cancer Council Australia and Australian Cancer Network, 2008.

5. Harvey NT, Chan J, Wood BA. Skin biopsy in the diagnosis of neoplastic skin disease. Aust Fam Physician 2017:46(5):289-94.

6. Dinnes J, Deeks JJ, Chuchu N, et al. Visual inspection and dermoscopy, alone or in combination, for diagnosing keratinocyte skin cancers in adults. Cochrane Database Syst Rev 2018:12(12):CD011901. doi: 10.1002/14651858. CD011901.pub2.

7. Reiter O, Mimouni I, Gdalevich M, et al. The diagnostic accuracy of dermoscopy for basal cell carcinoma: A systematic review and metaanalysis. J Am Acad Dermatol 2019;80(5):1380-88. doi: 10.1016/j.jaad.2018.12.026

8. Dinnes J, Deeks JJ, Chuchu N, et al. Dermoscopy, with and without visual inspection, for diagnosing melanoma in adults. Cochrane Database Syst Rev 2018;12(12):CD011902. doi: 10.1002/14651858. CD011902.pub2.

9. Carrera C, Marchetti MA, Dusza SW, et al. Validity and reliability of dermoscopic criteria used to differentiate nevi from melanoma: A web-based International Dermoscopy Society study. JAMA Dermatol 2016;152(7):798-806. doi: 10.1001/ jamadermatol.2016.0624.

10. Pizzichetta, MA, Talamini $R$, Stanganelli l, et al. Amelanotic/hypomelanotic melanoma: Clinical and dermoscopic features. $\mathrm{Br} J$ Dermatol 2004;150(6):1117-24. doi: 10.1111/j.13652133.2004.05928.

11. Menzies SW, Kreush J, Byth K, et al. Dermoscopic evaluation of amelanotic and hypomelanotic melanoma. Arch Dermatol 2008;144(9):1120-27. doi: 10.1001/archderm.144.9.1120.

12. Braun R, Lallas A, Marghoob A. Level 3: Intradermal nevi. Auenbruggerpl, Graz: Dermascopedia, 2018. Available at https:// dermoscopedia.org/w/index.php?title=Level_3: Intradermal_nevi\&oldid=13539 [Accessed 14 February 2020].

13. Macri A, Tanner LS. Cutaneous angiofibroma. Treasure Island, FL: StatPearls Publishing, 2020. Available at www.ncbi.nlm.nih.gov/books/ NBK482470 [Accessed 14 February 2020].

14. Lallas A, Moscarella E, Argenziano G, et al. Dermoscopy of uncommon skin tumours. Australas J Dermatol 2014;55(1):53-62. doi: 10.1111/ajd.12074.

15. Zaballos P, Ara M, Puig S, Malvehy J. Dermoscopy of sebaceous hyperplasia. Arch Dermatol 2005;141(6):808. doi: 10.1001/archderm.141.6.808. 